Copyright (c) 2010 SBPJor / Sociedade Brasileira de Pesquisa em Jornalismo

\section{ASSESSING THE CASE OF DENGUE IN ARGENTINA ZOO9 discrimination and fear}

\author{
MAXIMILIANO E. KORSTANJE \\ University of Palermo
}

\begin{abstract}
After almost a decade, the re-appearance of Dengue in Argentina caused panic and fears. Unlike Bolivia, Brazil and Paraguay where policies of preventions have been followed, the future of dengue is uncertain for Argentina; this paper does not have any political affiliation but emphasizes the role that mass media play in the coverage of epidemics. The question as to whether a newspaper or mass media corporation should maintain a minimum of objectivity is too complex to be resolved in this short article. However, we have so far set forth a model which will help other researchers to interpret topics of this nature in the future. In moments of disorder, uncertainty or disaster, societies experience a shift in the ways they perceive reality. As has been previously developed, uncertainty, gossip and ideological facets are inherent in all cases of social disturbances.
\end{abstract}

Key-words: Dengue outbreak; panic; mitigation; political fields.

\title{
INTRODUCTION
}

In March of 2009, panic emerged when the mass media distributed the news of an outbreak of Dengue, a disease originally eradicated in 1950 but which returned to the life of the Argentines after many years of absence. As a privileged observer, not only have we had the chance to record how events evolved but also to document considerable evidence to develop an all-encompassing theory of panic and threat perception. The questions why and when fear surfaces in day-to-day life seem to be secondary. Rather, the moot point here is for what purpose and how the mass media operate in contexts of instability or emergencies. Basically, Dengue is an illness which originated in tropical zones. In people symptoms begin with an unbearable fever prolonged for two or more days. Like Malaria, this disease is spread through infection by a mosquito called Aedes Aegypi. Once this mosquito has been infected, it propagates the virus to other healthy persons. Although in rare circumstances this seems to be fatal - only in cases of re-infection with different strains - the coverage of the Argentine mass media was dramatically aimed at emphasizing time and time again the disastrous 
effects of this illness. These newspapers published their articles with well-impacted and imperative headlines such as "Scientists say that the fight against Dengue failed", "Argentina is hit by the most virulent epidemic of Dengue in recent years" or "Dengue wreaks havoc in the northwest of Argentina".

After further examination, we find that issues of this magnitude and complexity should be studied from many perspectives. Our thesis is that emergency and disaster situations draw immediately the attention of the mass media. The processes involving how they cover these types of situations are threefold. We first encounter a phase linked to uncertainty in which population is not familiar with the situation. A couple of days later, this stage is accompanied by a phase of gossip in which fantasy predominates in circulated news, informal commentaries, and rumors that refer to new cases involving relatives, friends, colleagues or co-workers; this serves as a way to intellectualize the danger. Ultimately, a third ideological phase is characterized by the dissemination of concrete information. However, politics configure the basis for the construction of a mythical archetype which helps people to understand more about the reality before their very eyes. To the best of our knowledge, the mass media play a pivotal role in these circumstances. Of course, this exploratory-related paper does not intend to discuss technically the reasons why Dengue emerged after being hidden for many years, but qualitatively how people perceive pitfalls resulting from this kind of outstanding circumstances and what role is played by the mass media in this process.

\section{Initial Discussion}

Albeit abundant literature has been devoted to the research of the mass media's performance in cases of epidemics, natural disaster and social disturbance and in shaping public opinion in the First World where infrastructure resources are available for planning evacuation policies (Quarantelli, 1975) (Wenger and Friedman, 1986) (Quarantelli, 1982) (Quarantelli and Wenger, 1989) (Rodriguez, Diaz and Aguirre, 2004) (Quarantelli, 1990) (Tierney, 1994) (Mcneil and Quarantelli, 2008), less or little attention was given to how Journalism covers moments of disaster in the Third World because of ecological contamination by the industrial economies in the United States, China and Europe. The resurgence of new viruses as a result of "global warming" associated with a lack of material resources for dealing with health problems can wreak havoc in a large part of Latin America. Excuses related to poverty or material conditions 
in which people spend their daily lives are another important device used to explain why Dengue gradually advances. In this way, a pseudoscientific explanation mistakenly associates dengue with poverty.

One of more important scholars in the study of panic, E. L. Quarantelli envisages that "the essence of panic is the overt behavior that is marked by the setting aside of everyday social norms, even the strongest, such as parents abandoning their young children trying to save themselves in a lifethreatening crisis. Often implicit, there is the assumption in this view that this behavior of flight will occur only if there is a perception that there is a possibility of escaping from the threat. Disaster researchers in particular have emphasized that the hope of escape rather than hopelessness is what is involved. Persons who perceive themselves as totally trapped as in sunken submarines or collapsed coal mines do not panic because they see no way of getting away from the threat" (Quarantelli, 2001:5).

The fact is that fears are part of our emotional basis; panic should be understood as a social fact produced by a symbolic elaboration. One of pioneer projects regarding this theme was authored by the German sociologist, Ulrich Beck. At a time when the effects of capitalism on the environment are under debate, his book presents an historical analogy with the purpose of reconsidering a classical conceptualization of progress and development. In his introductory chapter, Beck argues that the process of modernity suffered a break with a nuclear accident which occurred in Chernobyl, Ukraine. After this tragedy, the perception of threats was radically altered. Unlike medieval travelers, who evaluated personal risks before departing, a new form of living the adventure is surfacing (Beck, 2006). By the way, an interesting research work conducted by $\mathrm{A}$. Mozgovaya in districts of Ukraine where still today there are traces of radioactivity found that $40 \%$ of teenager respondents said they were suffering fear, a sense of helplessness after the disaster while another $16 \%$ have lost dramatically their interest in life. From this perspective, females appear to be more affected than males. Migration constitutes as one of best possibilities for inhabitants of Brjansk and Tula. A second survey demonstrated that bondage declination as well as dependence on alcohol has multiplied in the population just after Chernobyl (Mozgovaya, 1993).

On the other hand, Beck suggests that global dangers are represented as collective, catastrophic and chaotic beyond the possibilities of individual reaction. To put this brutally, there is nothing one can do when the catastrophe is coming. In this context, Beck suggests that a shift of this magnitude is feasible in accordance with an increasing materiality 
as well as empowerment of productive forces. In this way, threats are implicitly derived as a product of the economic development which society has undergone, but sooner or later a situation of increasing dangers is too much for the level of response that society can tolerate, and the system definitely collapses. In opposition to bourgeois society, which maintained the line between poverty and wealth, modern societies face a new configuration of the social order. The fact is that this aforementioned transformation has given birth to a new kind of society known as "The Society of Risk" where fears and risk are indiscriminately distributed to all the strata of the structure (Beck, 2006).

The needs of mass consumption in association with a growing sentiment of fear paved the way for the advent of a new spirit of capitalism. As a result of this, the logic of appropriation, which characterized classical mercantilism in past decades, is replaced by its own antithesis, the logic of denial. It is not surprising that privileged groups hide collateral damages derived from non-sustainable consumption; their practices are justified thanks to the intervention of Science and Journalism. The underlying problem seems to be that duties and responsibilities are globalized at the same time that humankind jeopardizes its future by exhausting the non-renewable resources on earth as well as polluting the ozone layer. Implicitly or not, that blurs the boundaries between victim and culprit; but in perspective, whenever risks are denied, fears emerge. After further examination, Beck explains that in the traditional society of classes, groups configured their distinctions according to the style of consumption embodied in early socialization processes. Risks were conceived as well-known and experienced individually or internally, whereas in our times threats are beyond people's capacity for reaction.

In the hands of journalism or biology authorities, risks not only appear to have multiplied in recent years everywhere, but also to have diminished the cognitive sovereignty of citizens. In order to alleviate the burden caused by the perception of dangers, the market puts forward multiple alternatives of new products involving security objectives. Basically, Beck is concerned about the degradation of the environment because of toxic wastes. Since this new form of perceiving modernity obliges countries to combine efforts for the resolution of daunting risks, the quality of the community is being gradually transformed. In the passage from one type of society to another, notions such as equality, wealth and democracy are replaced by security, conflict and fears.

The idea of hierarchical distinction as a product of personal hard work evolves towards a much more complex construction in which nobody 
feels safe. Once again, fears of social descent which characterized industrialism are being replaced by a compulsory necessity of preventing "the worst"; a catastrophe becomes more shocking when it is unplanned than other misfortunes such as disease or poverty. Unpreparedness as well as the incubation of sentiments of anxiety gives rise to what Beck calls "The society of Fear". His main thesis is aimed at contrasting how in modern societies dangers are not circumscribed to individual reactions; in part, material imbalances generated by capitalism are reinvented reproducing an "Economic Drive" of first magnitude. In other words, even though global fears entail global responses, irregularities in the economy remain in an individual domain. This is because psychological necessities are restricted to their satisfaction and once this is done they take some time to be reactivated. Metaphorically speaking, the imposition of external risks on the minds of consumers comprises an unlimited oil well because it can never be satisfied. Emphasizing the historical background, Beck compares the transition from feudalism in the Middle Ages to classical capitalism in the XVIII and XIX centuries respectively. If this is correct, any economic production implies specific limitations and risks which not only are ignored but also symbolically manipulated and perpetuated. Whereas in the Middle Ages witchcraft, evilness and demons shaped the consciousness of theology in European societies, today "global risks" related to environmental contamination play a similar role in encouraging consumption according to the integrity of consumer issues (Beck, 2006). This situation became paradoxical because society is condemned to disappear from its own inception onwards. It is just a question of time.

Another interesting perspective regarding what people consider shocking is offered by R. Leurs, who examines through Kantian eyes how the attack against the World Trade Center (WTC) on Sept. $11^{\text {th }}$ can be expressed in terms of sublimity. Our philosopher is convinced that the concepts of mathematical and dynamic sublimity can be applied to the study of tragedies. In fact, Leurs synthesizes "mathematical sublimity occurs when an object is too large to be perceived as a whole, while dynamic sublimity is caused by frightening phenomena. In both instances, displeasure is succeeded by pleasure: mathematical sublimity indicates that we can make use of rhetorical reason and dynamic sublimity reveals a respect for the moral law within us" (Leurs, 2008:3). In other terms, the dimensions of tragedies are frightening only when they can be captured in the observer's mind. People remain unfamiliar with the reasons for and the effects of disaster. In these circumstances, the mass media play 
a pivotal role in transmitting news from one moment to another, thus shaping an opinion irrespective of the situation.

\section{The role of the mass media in the coverage of tragedies}

Even though sociological and psychological research have devoted considerable attention to determining how the mass media work in moments of uncertainty and terror (Bartlett, 1932) (Lorge, 1936) (Lazarfeld et al, 1944) (Cooper and Jahoda, 1947) (Freidson, 1953) (Klapper, 1963) (Papageorgis, 1963), it is often assumed that only after the Sept $11^{\text {th }}$ attacks on the WTC and a later frightening smallpox outbreak, scholars considered that the mass media should play a pivotal role in calming the population (Fischhoff, 2006). The question as to whether public opinion should be aware of everything that happens in communication issues has been nowadays re-considered. As Hovland has already studied in tragedies which were caused by a simulated Martian invasion transmitted by $\mathrm{O}$. Wells, in times of war people are highly predisposed to sudden evacuation than at other times (Hovland et al, 1953).

Jean Baudrillard contends that post-modernity is eroding the basis of hierarchal authority. In fact, the artifacts and objects of the culture are being abstracted to a point beyond their functionalities. The boundaries between consumer goods and consumers are certainly being blurred. The postmodernist consumer needs to feel the control of the environment even though he or she failed to consume the surrounding objects. The importance of esthetics in our postmodern world is associated with the symbolism of functionality. In other words, as Baudrillard put it, one of aspects that characterize the industrial realm in comparison with handicrafts seems to be the nuisance of subjectivity, the systematic reproduction of symbolic meaning. In this way, objects personalize human bondages re-signifying their functionality depending on the epoch. For example, a mirror can have different usages during the Middle Ages, Mercantilism and nowadays. Starting from this basic premise, symbolic and usage values of objects are limited to their organizational values. The main thesis of our author has recourse to the Nietzschean tension between Pathos and Logos, order and chaos, meaningful and meaningless. This convergence explains the roots of tragedy as the human need to intellectualize the nature of what is savage. Besides, there exist certain structural discourses that are imposed according to the meaning of objects. The tendency of postmodernism evidences a narcissism which is pathological. On one hand, it demands to be unique and exclusive subjugating the logic of the universe to our specific desire 
while on the other, it corresponds with the over-exposure of a very routine life (Baudrillard, 1995a: 20-24).

The rise of fear in postmodernist times is related to terrorism and spectacle. Both converge with the end of Hegelian dialectic because the observer became the observed. Baudrillard warns about recent difficulties of the audience to differentiate what is real from what is not. Man-made or natural disasters that many years ago surprised human beings today are being considered outstanding signs and visually commercialized in the mass media. As F. Nietzsche said, democracy in conjunction with Apollonian logic upends the reality of environments in a simple representation. However, things go from bad to worse, because Baudrillard realizes that there are no frontiers separating those who place fear and panic in everyday life. Terrorists or lay persons are two sides of the same coin. Political fear works as a mechanism of self-indoctrination and paves the way to total control. Terrorism is only an excuse for a much broader, deep-seated issue. Thus, Baudrillard argued in 1995 that "the Gulf War did not take place" (Baudrillard, 1995b). Today, it is not important who is the victim and who is guilty; both are representative of a new order which seems to be surfacing. A message of this caliber matches the contributions of previous scholars synthesized in this paper.

Whatever the case may be, in 1994 Dahlhamer and Nigg conducted a survey to determine the liaison between rumor and increasing risks. The paper contains an analysis regarding conditions needed for the transmission or progress of rumors and the difference between believers and non-believers during the widely-felt earthquake of Los Angeles in 1979. In their work rumor was defined as "a collective process that arises when adequate information is unavailable, from formal or legitimate sources, to interpret a problematic situation or event" (Dahlhamer and Nigg, 1994:2). The objective of this study was to describe how people interpret non-damaging events in the light of past information regarding similar ones. The randomly selected sample was made up of 519 participants who were interviewed by telephone about four previously-determined interpretations: a) it means a larger earthquake will not happen, b) this was a sign of another one which is coming soon, c) the possibilities of a new earthquake are surely uncertain, and d) this consisted of an after-shock of an earlier local earthquake. The findings of this investigation demonstrated that $36 \%$ of the respondents believed a rumor that the earthquake was a sign of another one that was coming, while $26 \%$ considered that the earthquake would have no future effects. With respect to the sources, respondents agreed that rumors came 
informally from friends, family and co-workers. In analyzing community attachment as a variable, a significant correlation can be established with the number of rumors heard. Secondly, respondents who believed that an earthquake was more or less unlikely within a year have less belief in rumors than others who stated that another earthquake would be possible during this period. Finally, Dahlhammer and Nigg acknowledge that interviewees who had fewer children at home showed less belief in rumors. In conclusion, "similar to community attachment, large families will have more children in school and therefore may have wider communication networks. This may increase the odds of hearing more rumors. The more rumors that are heard may lead to more rumors believed" (Dahlhammer and Nigg, 2004:21).

However, not only the mass media can be used as an instrument for awareness of the population in cases of disasters. For other scholars, popular culture can provide the audience with virtual examples that can be taken into account in moments of evacuation. Mentioning films such as Deep Impact or Dante's Peak, T. Wachtendorf admits that "although a strong argument can be made that an audience recognizes the difference between appropriate social actions in a movie versus appropriate behavior in real life, these representations are sometimes the only experience people have with disaster. The meanings these representations convey will therefore influence how we interpret real events around us" (Wachtendorf, 2004:3).

On the other hand, a paper by Kueneman and Wright examines how the mass media behave in cases of social disturbance and disasters. Based on a sample of 72 radio and television stations in 12 towns around the United States, researchers investigated social reaction in contexts of: a) civil disturbance only, b) natural disaster only, c) lootings combined with natural disaster and ultimately, d) none of these. The outcome of this fascinating investigation is that social excitability is found to be explicitly associated with the withholding of information. For this reason, stations in the largest towns had a general plan to follow in case of disaster or riots in order for panic not to spread (Kueneman and Wright, w/d). Nevertheless this study has a key methodological problem which should be reconsidered. There is a huge gap sometimes between what people say and do; it is possible that the mass media intend not to promote panic in moments of disaster or disturbance following the most rigid protocol in the dissemination of information. Nevertheless, this will depend on the magnitude and intensity of the disaster rather than on intentions previously manifested in an interview of mass media corporations. 


\section{Ethnic minorities and fear}

Although panic was a concept present in ancient Greece and Rome, Freud was the first scholar who took into account and documented its real implications and consequences with regard to patients. In the case of "little Hans" (a boy 5 years old) there has been an episode of fear caused by the possibility of losing his mother's love. The birth of his sister in combination with a competitive liaison with his father generated ambivalent feelings initiated by a prior basic fear of castration. These kinds of sentiments where love and hate coexist resulted in an attempt to prevent a troublesome psychological disintegration (dissociation).

With this background in mind, fear is experienced internally as a response to avoid self-destruction by means of an extrapolation to an external object where all destructive feelings are deposited (Freud, 1998: 11-19). From this it follows that other aspects like fantasy or anguish play a pivotal role in determining prerequisites for the appearance of panic. More precisely, this point was respected and criticized by other scholars like Klein (1987), Ward (2001), Winnicott (1996) and Bleichmar (1991). Applying this theory to social contexts, in cases of tragedies ethnic minorities are discriminated as a form of alleviating the social tension society experiences (xenophobia).

\section{Dengue in Argentine Mass Media}

The following lines were inspired by a comprehensive and allencompassing participant and non-participant observation during the months of March, April and May in the city of Buenos Aires. Even if a study like this is restricted only to an urban-related area, its results can be applied to other similar locations. The phase of uncertainty appeared at the time the first cases of dengue were detected and accordingly divulged by the mass media. In addition, the role of the observer remains hidden on combining individual in-depth interviews with newspaper coverage.

As Fischoff put it, "people have difficulty making decisions about events that they have never experienced. In effect, they do not really know what they want nor what it would mean to them" (Fischhoff, 2006:476). Technically, it is unfortunate that no vaccination was available for dengue at the moment. This problem associated with re-infection possibilities caused fear and panic in the population. The outbreak was initially found in the Province of Chaco located in the north of Argentina on the frontier with Paraguay. Immediately dengue was propagated to other provinces such as Salta and Catamarca and reached Buenos Aires. At the moment, the Health Bureau registers more than 20,000 infected persons. At a 
hospital in Salta, scientists have come across a case of dengue in a newborn baby who surely was contaminated during gestation.

\section{Uncertainty}

Panic, fear and terror emerge whenever persons are unfamiliar with the backdrop in which they dwell. In any event the problem is who will provide information, when or what interests these sources pursue. Researchers are prone to pay no attention to moments of uncertainty in their studies; perhaps this is because information is scant and difficult to trace coherently. P. Dupuy mentioned a case studied by E. Quarantelli when news of an unexpected earthquake was omitted during the game between the San Francisco and Oakland teams; surprisingly, viewers continued enjoying that spectacle without any problems (Dupuy, 1999). As a consequence, Dupuy reconsiders that panic only is possible if people do not find the way out. By the way, when news about Dengue surfaced for the first time in TV, Radio and the Press, one of first sentiments inhabitants of Buenos Aires felt was astonishment. At that point, people were disoriented and confused by a great diversity of speculations, ranging from the belief that the Aedes Aiyipi mosquito transmits the illness to people to the notion that people can be infected through personal contact with other passer-bys. In these circumstances, interviewees do not show any interest in talking about dengue nor about its causes or effects. At this stage, our own observations confirmed that there is a lapse of silence in which case the audience takes time to receive the appropriate information from different sources.

Television and radio are the most consulted sources followed by newspapers and gossip. In this instance, rumor had not a stronger influence in porteños (a colloquial expression denoting residents of Buenos Aires). The mass media increasingly repeated -again and again -the number of new infected cases. With impacting headlines such as "Dengue landed in Buenos Aires, 15 cases detected"' or "Dengue moves to Bolivia and Brazil as well"2, the mass media disseminate fear throughout the population in Buenos Aires and the main cities. The purpose of these alarms is to make the audience aware of the problem. Ambiguously, the mass media play a pervasive role because on one hand they care about practical courses of action to mitigate the effects of dengue whereas on the other they trigger the panic emphasizing how the outbreak grows daily. In this connection, news related to how professionals controlled the situation earlier or in other countries is essential. With reference to thousands of infected cases in Brazil and Bolivia and the ways these countries diminished dengue, $L a$ 
Nación reported "In Brazil, more specifically, in the state of Bahia, there were at least 29 dead and 32,306 affected persons since the beginning of this year, official sources reported. The number of infected victims is $305 \%$ higher than in 2007"... These shocking lines are accompanied by other more optimistic ones which say "in Bolivia cases of dengue were dramatically reduced in recent weeks and health officials estimate that within one month this terrible disease can be eradicated". ${ }^{3}$

As mentioned in the previous discussion, ambivalence of this magnitude is associated with the emergence of panic and fear in the social imagination. As Freudian theory emphasized, social fears allow us to create coherence and order. A stage of uncertainty is characterized by ambiguity and contrasting feelings which disorient the audience. The mass media release a considerable amount of news and information that sometimes are not coherently classified. Unless otherwise resolved, uncertainty is replaced also by ambiguity.

\section{Gossip}

Once angst settled down in the minds of the porteños, other new element surfaced: gossip. We can generally define gossip as "any rumor about private or public affairs of people that are unproven". Etymologically, this word stems from the old Anglo-Saxon godsibb (divided into god and sib), a word designating godparents. In the $16^{\text {th }}$ century, this took on a new meaning related to a woman who delights in idle talk. In addition, the most important functions of gossip are threefold: a) reinforcing the social order by means of speech-related manipulation, b) fostering a sense of community and contiguity, and c) it can be manipulated as passive aggression for political purposes.

Typically, in the fifth and sixth weeks following the appearance of dengue, every type of rumor arises. Absence of co-workers or illnesses with similar symptoms such as influenza leads to dramatization, fear and speculation. People appear not to tolerate uncertainty and invent many possible explanations of events. After Nicholas (male, 25 years old) took sick leave from work because of classical influenza, these two fragments were selected from many other informal interviews, "Nicholas has been infected by dengue, most surely that mosquito has bitten him. I have no further information about him, but I remember he had symptoms of dengue: high fever, weakness, and pain behind the eyes" (Leandro, male, 23 years old). Needless to say, not only Nicholas did not have dengue but also he was returned to work after one day in bed. Nevertheless, when ambivalence cannot be tolerated, physical and psychological 
discrimination present an alternative measure. This was the case of Romina (female, 32 years old) who considered that an efficient course of action to prevent dengue's proliferation was the creation of ghettos where sick persons should be placed.

In her words "it is unfortunate that dengue does not discriminate by class or race, this not only is a fault of the State but also of those niggers, aborigines, and immigrants who live in misery. The question is why should I face this situation? ...If you ask me, a interesting solution for this epidemic is the isolation of Buenos Aires from Salta, Chaco and Catamarca. You figure it out, 20\% of the mosquitoes in Buenos Aires are aedes aegypi, if we permit the entrance of travelers coming from these provinces or from Bolivia or Paraguay, the current cases will be multiplied". As a whole, geographical or ethnic discrimination is combined with other broader issues such as ideology and political articulation. A public interview conducted by Telenoche News with the wife of the first infected person, a lawyer 60 years old residing in the Ciudadela district, revealed a similar phenomenon. The woman said, "We have recently visited Liniers which was like being in Bolivia". Of course, her statement was ironically oriented to argue that Bolivian immigrants living in Liniers were guilty of spreading this frightening epidemic. Implicitly, she suggested that Bolivians, and only they, transmit dengue.

But it appears to be a surface manifestation of a more deepseated issue. According to the contribution of U. Beck, in the society of risk, dangers arise indistinctly from class, race or religious affinity. Furthermore, it is often hypothesized that unexpected events make a deep impact on minds causing episodes of anxiety and anguish. As a consequence, people psychologically develop a defense mechanism so that the prevailing disorder can be diminished. For this reason, in cases of tragedies or unforeseeable events people follow two paths: a) considering abstract excuses that permit them to rationalize the reasons behind the disaster, or b) externalizing the guilt in the direction of others. From this perspective, it is not surprising that interviewees - regardless of age or gender - were quick to declare that some close acquaintances of theirs caught dengue quite aside from whether it was real or not.

\section{Ideology}

Defining what ideology is really seems to be a difficult task. Tentatively, it can very well be defined as "a set of ideas articulated politically for the purpose of restoring a previous social order and also 
applied to public matters". For others scholars, ideology works as an instrument for social reproduction. Whatever the discussion may be, the third phase of dengue in Argentina was characterized by the presence of ideology and political struggle in health issues. Immediately, the health minister in Chaco - where the first cases had been initially recorded - was put under a cloud and finally removed.

Under this perspective, G. Ocaña - the National Health Minister was seriously criticized because of her negligence in forecasting and preventing this epidemic. Even the Senate was involved in a public conflict when FPV senators refused to deal with the emergency law. Their argument was that winter and lower temperatures would defeat dengue in the next few hours and nationwide exposure would be selfdefeating for tourism and other industries. The debate continued in the interior of this institution and the mass media reflected the events as follows: "Senate does not vote on the emergency measure for dengue: the upper house of congress postponed the discussion of an affair that worries all Argentines".

Other types of coverage emphasized the responsibility of the State in the outbreak of dengue in detriment to public health as well as the impediment to approving a law that helps to fight against this disaster. Dengue not only struck Argentina individually but also shook the bases of politics. Discussion followed in households and workplaces in favor or not of official policies. Older stereotypes and positions were reinforced depending on which side the contenders were. For example, on April 16 Clarin published "cases of dengue in Buenos Aires were confirmed". Highlighted in red, this newspaper - a staunch enemy of former president Nestor Kirchner-said "Kirchnerism prevented the Senate from voting on the health emergency law". This column contained information that emphasized the danger of possibly related native cases of persons who were infected despite the fact that they had never visited the province in quarantine. The argument was aimed at highlighting that dengue landed in Buenos Aires because of the inefficacy of the government and a lack of resources and policies of prevention. In successive pages, the newspaper reported the blocking of the approval of the emergency law putting the blame on Cristina Kirchner, the wife of Nestor and the current president of Argentina ${ }^{5}$. Once again, this slippery matter was transformed into a political arena in which individual and more traditional interests entered into conflict. On the other hand, El Argentino, a newspaper loyal to the government, does not make any specific reference to 
dengue or to the responsibility of officials in that connection.

\section{Conclusion}

Unlike Bolivia, Brazil and Paraguay where policies of preventions and mitigation have been followed, in Argentina the future of dengue is uncertain; this paper does not have any political affiliation but emphasizes the role that the mass media play in the coverage of epidemics. Mass-media and advertising play a pivotal role in the multiplication of fear in the core of societies. The question as to whether a newspaper or mass media corporation should maintain a minimum of objectivity is too complex to be resolved in this short article. However, we have so far set forth a model which will help other researchers to interpret topics of this nature in future. In moments of disorder, uncertainty or disaster, societies experience a shift in the ways as they perceive reality. Our thesis is that uncertainty, gossip and ideological facets are key-factors inherent in almost all cases of social disturbance.

In Argentina we have found that the discourse of interviewees takes two courses of action: on one hand, they create a circle of exclusion of otherness to protect and alleviate the in-group anxiety. They invent possible explanations about the cause of the phenomena aside from how credible they may be. People mention that they know some friends or co-workers who supposedly were infected by dengue. The underlying issue is that the perceived proximity of threats reduces the odds of facing shocking pitfalls. If the mass media disseminate impacting and scary conceptualizations, citizens derive other ways for materializing fear of risks. When this happens, gossip appears to us to be a fruitful vehicle for further understanding. What causes more suffering in people is not death or illness as such, but the reminder that life remains beyond their possibilities of comprehension. We strongly believe that the model resulting from this paper can be very well replicated in other studies.

More precisely, on April $26^{\text {th }}$ a new danger of an epidemic appeared in Mexico; a new mutation of classical Swine Flu took more than 100 lives and can spread to other countries such the United States. Since an emergence was rapidly declared by the World Health Organization, the role of the mass media in this process should be thoroughly investigated in future research works. Can this new case replicate the model we observed in this paper? 


\section{| NOTES}

1 Clarín, "Dengue Landed in Buenos Aires: 15 cases detected". April 1, 2009.

2 La Nación. "Dengue moves to Bolivia and Brazil as well”. March 30, 2009.

3 La Nación. “Dengue moves to Bolivia and Brazil as well”. March 30, 2009.

4 El Parlamentario.com, "Senate does not vote on the health emergency law". April 15, 2009. Available at http://parlamentario.com/noticia-21307. html.

5 Clarin, "Local cases of dengue in Buenos Aires confirmed". Edition LXIV. N. 22.738. Page. 28.

\section{| BIBLIOGRAPHY}

BARLETT, F. C. (1932). Remembering. A study in experimental and social psychology. Cambridge, Cambridge University Press.

BAUDRILLARD, J. (1995a). The systems of the objects. Mexico, Siglo XXI.

BAUDRILLARD, J. (1995b) The Gulf War Did Not Take Place. Sydney, Power Publications

BECK, U. (2006). The society of Risk: towards a new modernity. Barcelona, Paidos.

BLEICHMAR, H. (1991). La Depresion un estudio psicoánalitico. Buenos Aires, Ed. Nueva Vision.

COOPER, E and Jahoda, M. (1947). "The evasion of Propaganda: how prejudiced people respond to anti-prejudice propaganda”. Journal of Pshychology. Vol. 23, Número 1: 15-25.

DAHLHAMER, J. and Nigg, J. (1994). "An Empirical investigation of rumoring: anticipating disaster under conditions of uncertainty". Disaster Research Center, Preliminary Paper 216

DUPUY, J. P. (1999). The Panic. Barcelona, Paidos.

FISCHHOFF, B. (2006). "The Psychological Perception of Risk". In Homeland Security. Kamlen, D. New York, McGraw-Hill. Pp. 463-492.

FREIDSON, E. (1953). "Communication Research and the concept of the mass”. American Sociological Review. Vol. 18 (3): 313-317.

FREUD. S. S. (1998). "Analysis of a phobia in a five-year-old boy: little Hans Case”. Obras Completas. Vol X. Buenos Aires, Amorrortu.

HOVLAND, C. (1953). Communication and Persuasion, psychological 
studies of opinion change. New Haven, Yale University Press.

KLAPPER, J. T. (1963). The Science of human communication. Nueva York, Basic Books.

KLEIN, M. (1987). "Psychoanalysis in children". En Obras Completas de Melanie Klein. Tomo 2. Buenos Aires, Paidos.

KUENEMAN, R. and WRIGHT, J. E. (w/d). "Disaster Research Center, Preliminary Paper 17. No date specified in paper.

LAZARFELD et al. (1944). The people choice. How the voter makes up his mind in a presidential campaign. New York, Columbia University Press.

LEURS, R. (2008). "The Cultural Sublime or... Immanuel Kant watching the 9/11 attacks on TV". The Philosopher, Vol. LXXXXXVI, no. 2. Available at http://www.the-philosopher.co.uk/sublime.htm.

LORGE, I. (1936). "Prestige, suggestion, attitudes". Journal of Social Psychology. Vol 8 (2): 386-402.

MCNEIL, S. and Quarantelli, E. (2008). "Past, Present and Future: building and interdisciplinary disaster research center on a Half-century of Social Science disaster research". Disaster Research Center, Preliminary Paper 362.

MOZGOVAYA, A. (1993). "Social Consequences of the Chernobyl Catastrophe: some results of sociological research". Disaster Research Center, Preliminary Paper 198.

PAPAGEORGIS, D. (1963). "Barlett effects and persistence of induced opinion change". Journal of Abnormal and Social Psychology. Vol. LXVII (1): 61-67.

QUARANTELLI, E. (1975). "Panic Behavior: some empirical observations". Disaster Research Center, Preliminary Paper 20

QUARANTELLI, E. (1982). "People's reactions to emergency warnings". Disaster Research Center, Preliminary Paper 75.

QUARANTELLI, E. (1990). "The Mass media in disasters in the United States". Disaster Research Center, Preliminary Paper 1990.

QUARANTELLI, E. (2001). "The Sociology of Panic". Disaster Research Center, Preliminary Paper 283

QUARANTELLI, E. and Wenger, D. (1989). "A cross sociological comparison of disaster news reporting in Japan and United States". Disaster Research Center, Preliminary Paper 142.

RODRIGUEZ, H. Diaz, W and Aguirre, B. (2004). "Communication risk and warnings: an integrated and interdisciplinary research approach". Disaster Research Center, Preliminary Paper 337.

TIERNEY, K. (1994). "Sociology's unique contributions to the study of risk". Disaster Research Center, Preliminary Paper 204. 
WACHTERNDORF, T. (1999). "Exploring the Popular culture of disaster". Disaster Research Center, Preliminary Paper 290.

WARD, I. (2001). The Phobias. Buenos Aires, Longseller.

WENGER, D. and Friedman, B. (1986). "Local and National Media coverage of disaster: a content analysis of the Print media's treatment of disaster myths". Disaster Research Center, Preliminary Paper 185a.

WINNICOTT, D. (1996). Home is where we start from: essays by a psychoanalyst (paperback). Buenos Aires, Paidos.

Maximiliano E. Korstanje is a Lecturer in the Economics Department at the University of Palermo, Argentina, Professor Maximiliano Korstanje holds a B.A. in Tourism and in Anthropology (University of Moron, Argentina) and is a Ph.D. candidate in Social Psychology (John. F. Kennedy University, Argentina). One of his areas of expertise is the study of panic flights in disaster situations in modern and ancient times (Roman Empire) as well as the risk perception theory applied to travel and tourism. As a specialist he is concerned with the effects of Sept- 11 th and other man-made and natural disasters on tourism and hospitality. In addition, Korstanje has published more than 230 articles in peer-review journals throughout the world, as well as 10 books. 